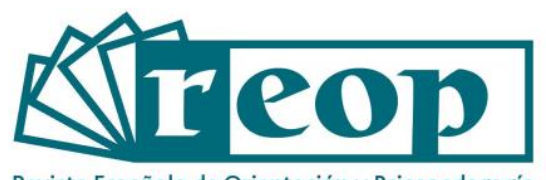

Revista Española de Orientación y Psicopedagogía

\title{
OBJETIVO CINE1 3: ANÁLISIS DEL ÉXITO Y ABANDONO EDUCATIVO. IMPLICACIONES PARA LA ORIENTACIÓN
}

\author{
OBJECTIVE ISCED 3: ANALYSIS OF EDUCATIONAL SUCCESS AND DROPOUT. \\ IMPLICATIONS FOR GUIDANCE
}

\author{
Javier Morentin-Encina ${ }^{2}$ \\ Universidad Nacional de Educación a Distancia. Facultad de Educación. Departamento de \\ Métodos de Investigación y Diagnóstico en Educación I. Madrid, España \\ Belén Ballesteros Velázquez \\ Universidad Nacional de Educación a Distancia. Facultad de Educación. Departamento de \\ Métodos de Investigación y Diagnóstico en Educación I. Madrid, España
}

\section{RESUMEN}

La preocupación por el Abandono Temprano de la Educación y Formación (ATEF) es una constante en políticas europeas y nacionales, justificando medidas educativas específicas para reducirlo. Aunque no disponemos de evaluación oficial sobre la eficacia de estas, observamos que el porcentaje de abandono en España viene disminuyendo en los últimos años. Desde el punto de vista de la orientación educativa, interesa evidenciar las transiciones entre distintas etapas hasta la consecución del nivel CINE 3: ¿cómo se produce la progresión en secundaria obligatoria hacia secundaria postobligatoria? ¿cómo incide la FPB en el cálculo del abandono? Para ello, se han realizado análisis comparados y longitudinales a partir de los datos proporcionados por el Ministerio de Educación y Formación Profesional (MEFP). Los resultados muestran que la mayoría de las personas tituladas en secundaria obligatoria continúan estudiando con éxito, contribuyendo así a la reducción del ATEF. Sin embargo, un 30\% del alumnado que comienza sus estudios en ESO, no llegan a terminarlos, siendo aproximadamente dos terceras partes de ese porcentaje

\footnotetext{
${ }^{1}$ Clasificación Internacional Normalizada de la Educación.

${ }^{2}$ Correspondencia: Javier Morentin-Encina. Correo-e: imorentin@edu.uned.es, web: https://www2.uned.es/grupointer/
} 
quienes abandonan antes de 4․ En el momento actual, la reducción del ATEF está relacionada con la distinta consideración de la FPB y los PCPI's a los que sustituye. Siendo el éxito de la titulación en FPB menor que en los PCPI's, su contribución a la mejora de la cifra de abandono es clara porque permite certificar un nivel CINE 3. Por ello, urge valorar el funcionamiento y logro de medidas de flexibilización en centros educativos que faciliten el éxito escolar.

Palabras clave: abandono escolar, orientación educativa, formación profesional, política educacional, diversificación de la educación.

\section{ABSTRACT}

Concern about Early School Leaving (ESL) is a constant in European and national policies, justifying specific educational measures to reduce it. Although we do not have an official evaluation of the effectiveness of these measures, we note that the percentage of dropouts in Spain has been decreasing in recent years. From the point of view of educational guidance, it is interesting to highlight the transitions between different stages up to the achievement of ISCED level 3: How does the progression from compulsory to post-compulsory secondary education take place? How does Basic Vocational Education Training (BVET) affect the calculation of drop-out rates? To this end, comparative and longitudinal analyses have been carried out, based on data provided by the Ministry of Education and Vocational Training (MEFP). Results show that the majority of those with compulsory secondary education continue to study successfully, thus contributing to the reduction of ESL. However, $30 \%$ of the students who enroll in Secondary Education (ESO) do not complete this level, and approximately two thirds of that percentage drop out before the $4^{\text {th }}$ year. At present, the reduction in ESL is related to the different consideration of the BVET and the PCPIs that it replaces. Though graduation from BVET is lower than that of the PCPI, its contribution to improving the drop-out rate is clear because it allows for the certification of ISCED level 3.

Key Words: dropping out, educational guidance, vocational training, educational policy, diversification of education.

\section{Cómo citar este artículo:}

Morentin-Encina, J. y Ballesteros Velázquez, B. (2021). Objetivo CINE 3: análisis del éxito y abandono educativo. Implicaciones para la orientación. Revista Española de Orientación y Psicopedagogía, 32(2), 7-26. https://doi.org/10.5944/reop.vol.32.num.2.2021.31275

\section{Introducción}

La educación es condición necesaria para el bienestar social. Las políticas gubernamentales a nivel europeo y nacional asumen esta afirmación como motor para la regulación de sus sistemas educativos y apuestan por alcanzar máximos niveles de formación en la población. La orientación 
educativa tiene el compromiso de consolidar los cambios necesarios en el entorno escolar que faciliten en los jóvenes el logro del éxito educativo y el desarrollo de un itinerario de vida con sentido (Romero et al., 2012).

La preocupación por el desenganche educativo es un eje prioritario desde el Consejo Europeo de Lisboa del año 2000, siendo en el Consejo Europeo de Bruselas (2003) donde se expuso por primera vez la necesidad de reducir el Abandono Temprano de la Educación y la Formación (ATEF), entendido como porcentaje de personas entre 18 y 24 años que no prosiguen estudios posteriores a la secundaria básica. A partir de este momento toma fuerza el concepto de ATEF como unidad de medida. La importancia otorgada a la cuestión del abandono tiene que ver con sus implicaciones más allá del nivel académico conseguido; la Comisión Europea (2019a) relaciona el abandono con menos empleabilidad y menos participación en la vida adulta.

El interés por reducir el abandono en España coincidió en el 2003 con el momento de graduación de la primera cohorte de estudiantes de secundaria obligatoria que finaliza sus estudios obligatorios a los 16 años, según establecía la LOGSE, evidenciando consecuencias notables en las cifras de abandono en un sistema educativo incapaz de dar una respuesta satisfactoria a la diversidad del alumnado (Alegre, 2010; Martínez García, 2012; Torres Santomé 2008, 2017; Bonal, 2018). Como resultado, una buena parte no continúa estudios más allá de la etapa obligatoria o, incluso, no consigue titular en secundaria. Las altas cifras de abandono justificaron que la Comisión Europea estableciera un menor nivel de exigencia en la reducción del ATEF en nuestro país, fijando el 15\% para el año 2020 (Comisión Europea, 2010).

La observación de la evolución del ATEF en España muestra una disminución progresiva desde 2009, aunque no se ha conseguido reducirlo al nivel marcado por la UE. Nos interesa conocer a qué se debe, si puede ser atribuido a las medidas y estrategias implementadas para la transición de los estudiantes en las distintas etapas escolares. A partir de ahí, se espera contribuir a la reflexión y práctica de la orientación como facilitadora de una progresión satisfactoria. El refuerzo de la orientación académica y profesional en los centros educativos figura entre las medidas destacadas por el Consejo Económico y Social para la prevención del desenganche escolar (Miñaca y Hervás, 2013).

El presente artículo se estructura desde este interés inicial. Para ello, comenzamos con una breve presentación de la atención educativa ofrecida durante los últimos años para el logro de esta reducción, donde se pone de manifiesto la flexibilidad-inestabilidad de las medidas y la ausencia de evaluación que avale su logro.

\section{De la preocupación a la acción: medidas educativas y orientadoras}

En el momento en que Europa establece como hito la reducción del abandono nuestro sistema educativo era (y es) uno de los que peores cifras presenta. Por ello, la respuesta a este imperativo se ha traducido en medidas específicas en las sucesivas leyes que regulan nuestro sistema educativo: la Ley Orgánica de Educación (LOE, 2006) y la Ley Orgánica para la Mejora de la Calidad Educativa (LOMCE, 2013), siendo la lucha por el abandono una constante en ambas.

A partir de estos marcos legislativos emergen las medidas y propuestas de orientación educativa que pretenden ofrecer un avance para la consecución de este reto. Muy brevemente se presenta una síntesis de lo que han venido proponiéndose como vías para afrontar la problemática del abandono en las dos últimas leyes educativas. 


\section{Orientación educativa a través de la flexibilización y adaptación curricular}

La LOE dispuso como medida de atención a la diversidad los Programas de Diversificación Curricular (PDC), dirigidos a estudiantes de $3^{\circ}$ y $4^{\circ}$ de ESO con dificultades para superar esta etapa educativa. Su objetivo era que los estudiantes pudieran concluir la secundaria a través de la adaptación de los contenidos y orientación educativa: grupos más reducidos y mayor tiempo de tutoría. Se estima que un $70 \%$ de los estudiantes que participaba en estos programas titulaban (Martín Ortega, 2000), aunque no se disponen datos sobre su evolución posterior. Icart y Suñé, (2019) destacaban como claves de éxito de los PDC, entre otras, el planteamiento a medio plazo del programa, la posibilidad de incorporación antes de tercero de ESO, el trabajo con grupos reducidos de 10 a 12 personas y la experiencia y preparación del profesorado. Navarro Hinojosa (2006) identificaba aspectos clave del programa desde el punto de vista del alumnado: eran menos en clase y recibían más ayuda del profesor; se enteraban mejor, les resultaba más fácil y, consecuentemente, conseguían mejores calificaciones que, a su vez, les reforzaba su autoestima.

Dichos programas fueron sustituidos en la LOMCE por el Programa de Mejora del Aprendizaje y del Rendimiento (PMAR), destinado a los estudiantes de $2^{\circ}$ y $3^{\circ}$ de la ESO, cuyas trayectorias presentan riesgo de desenganche, fracaso y abandono, (Amer y Mir, 2017). Su objetivo es ofrecer la preparación necesaria para que los estudiantes que lo cursan puedan proseguir $4^{\circ}$ de ESO en su grupo ordinario de clase. En estos programas se potencia la acción tutorial como recurso educativo para dar respuesta a las necesidades de aprendizaje del alumnado, así como al trabajo en relación con las familias y servicios sociales.

La reciente implantación de los PMAR dificulta la evaluación de sus resultados. Sin embargo, algunas apreciaciones son derivadas directamente del análisis de la propuesta en sí. Los Departamentos de Orientación (DO) facilitan la flexibilización metodológica: menos volumen de contenidos y de manera más adaptada posibilitan una atención más personalizada a los estudiantes ya que las ratios no superan los 15 alumnos. Además, los DO permiten un seguimiento individualizado al alumnado y permanecen en constante comunicación con las familias o servicios sociales. La continuación de estos programas pone en evidencia una paradoja explícita: la transición de los PMAR a la secundaria ordinaria para la consecución del graduado escolar. Como señalan Corujo et al. (2018), "es contradictorio que los estudiantes que durante dos cursos han recibido un nivel más adaptado del currículum a sus características, luego vuelvan a la vía que les ha hecho fracasar" (p. 36). La ruptura con la rigidez de la etapa secundaria y la flexibilización que ofrece esta medida de atención a la diversidad quedan entrecomilladas, como expresan Tarabini y Montes (2015). En este punto, los DO dan respuesta a las necesidades de orientación de todo este alumnado que, principalmente, se enmarcan en dos ámbitos: por una parte, la orientación personal dirigida a recuperar el autoconcepto y la autoconfianza; de otra, la orientación destinada a un proyecto profesional y la elección adecuada de la formación necesaria para ello (Romero et al., 2012).

\section{La orientación para la iniciación profesional como opción educativa}

La reducción de políticas públicas de apoyo a la formación y a la inserción social y profesional, acercan los niveles de desempleo juvenil a más de la mitad de las personas de 16 a 24 años (Salvá-Mut et al., 2014). Desde Europa se reconoce el interés de fomentar programas de formación profesional para luchar contra el abandono, apostando por la necesidad de dotar de una oferta de calidad ajustada a la demanda del mercado laboral, reforzar la formación del profesorado, flexibilizar el sistema y, en definitiva, promover una imagen positiva de la formación profesional (Cedefop, 2016).

En España, la introducción al ámbito profesional para la continuidad en la formación fue una medida contemplada en la LOE con los Programas de Cualificación Profesional Inicial, (PCPI) 
destinados a jóvenes entre 16 y 21 años que no habían obtenido la certificación en ESO ni ninguna titulación de formación profesional. El programa quedaba estructurado en dos ámbitos: el obligatorio (con formación básica general y formación profesional específica) y el voluntario, con posibilidad de obtener el título de ESO. La acción tutorial en estos programas resultaba clave para que los estudiantes concluyeran este ciclo con éxito (Romero-Rodríguez et al., 2015).

La evaluación de los resultados de los PCPI no queda registrada en informes nacionales, aunque ha sido objeto de estudio en diversas comunidades y desde iniciativas particulares. Así, la valoración del impacto de los PCPI en Cataluña, llevada a cabo en el curso 2008-09, puso de manifiesto una modesta contribución (3\%) de estos programas para el reenganche con la ESO y, aunque repercutió favorablemente en el aumento de matrícula de los ciclos medios de Formación Profesional no se tradujo después en mayor tasa de graduación (Blasco y Casado, 2013). En Andalucía se dispone de otro estudio que pone de manifiesto el aumento de matrícula en los $\mathrm{PCPI}$, aunque la transición hacia el $2^{\circ}$ curso, aquel que le lleva a poder titular en secundaria, registra una baja en torno al 50\% (Marín et al., 2014). El estudio no incluye datos que informen de la continuidad de estos estudiantes, por lo que no podemos derivar una valoración completa del impacto de estas medidas. En esta misma línea se inscriben otros estudios de interés, como el realizado por Aramendi y Vega (2013), que inciden en la organización de los procesos de enseñanza aprendizaje, la organización del centro y las estrategias orientadoras desarrolladas en estos ciclos formativos, aunque no aporta datos sobre consecuencias en la continuidad de los estudios.

Los PCPI fueron sustituidos en la LOMCE por la Formación Profesional Básica (FPB) (LOMCE, Disposición final quinta, ap. 4), orientada a facilitar la continuidad de los estudiantes en el sistema educativo y proseguir estudios postobligatorios en la línea marcada por la Comisión Europea (Sarcedo-Gorgoso et al., 2017).

Podrán acceder a ella, a propuesta del profesorado y del consejo orientador, los estudiantes que hayan cursado $3^{\circ}$ de la ESO o, con carácter excepcional, $2^{\circ}$, con la condición de que tengan 15 años o los cumplan en el año natural y que reúnan el consentimiento de sus padres/madres o tutores/as. Su duración es de dos años, siendo el segundo un curso orientado a la obtención del Graduado en ESO. Inicialmente la opción de graduarse en secundaria no se contemplaba en la FPB, si bien el Real Decreto 1058/2015 lo modificó estableciendo la posibilidad de conseguirlo a través de una evaluación final. Sin embargo, pese al corto período de implantación de estas enseñanzas, los datos revelan un alto porcentaje de estudiantes que desaparecen en el paso del primer curso al segundo, siendo aproximadamente la mitad los que permanecen, con grandes diferencias entre las comunidades autónomas. Por tanto, el propósito de facilitar la continuidad de los estudios a partir de la FPB tiene un alcance limitado y nos hace cuestionar la valoración de esta formación como medida para frenar el ATEF. Con todo, pese a estas cifras, se esconde lo que Bolívar (2013) denomina juego de "ingeniería estadística", que incidirá en una imagen favorable para el cómputo del abandono y el ajuste al mandato de Europa. Para entenderlo, necesitamos clarificar las claves conceptuales que explican la repercusión favorable de la FPB en la reducción del abandono:

- Nivel educativo que certifica. La FPB abre un nuevo escenario para el cómputo del ATEF. Si se consigue titular en FPB no se computa como abandono, es decir, se considera a la FPB como estudios postobligatorios. Este hecho contrasta con que los contenidos de la FPB sean algo más reducidos que los de la ESO (art. 42, LOMCE) y, sin embargo, esta titulación quede certificada por encima del graduado en ESO, al igual que un bachiller o CFGM. También contrasta con el hecho de que la FPB y los PCPI, a los que sustituyen, compartan el mismo perfil de estudiantes, pero certifiquen formaciones finales con distinto nivel (Clasificación Nacional de Educación, 2016). En el caso de los PCPI se computa como CINE 2 y la FPB como CINE 3 (Figura 1). Este hecho, tiene consecuencias estadísticas para el cómputo del ATEF, pues los estudios clasificados como CINE 3 no forman parte del abandono. 


\section{Figura 1}

Niveles CINE antes y después de la LOMCE

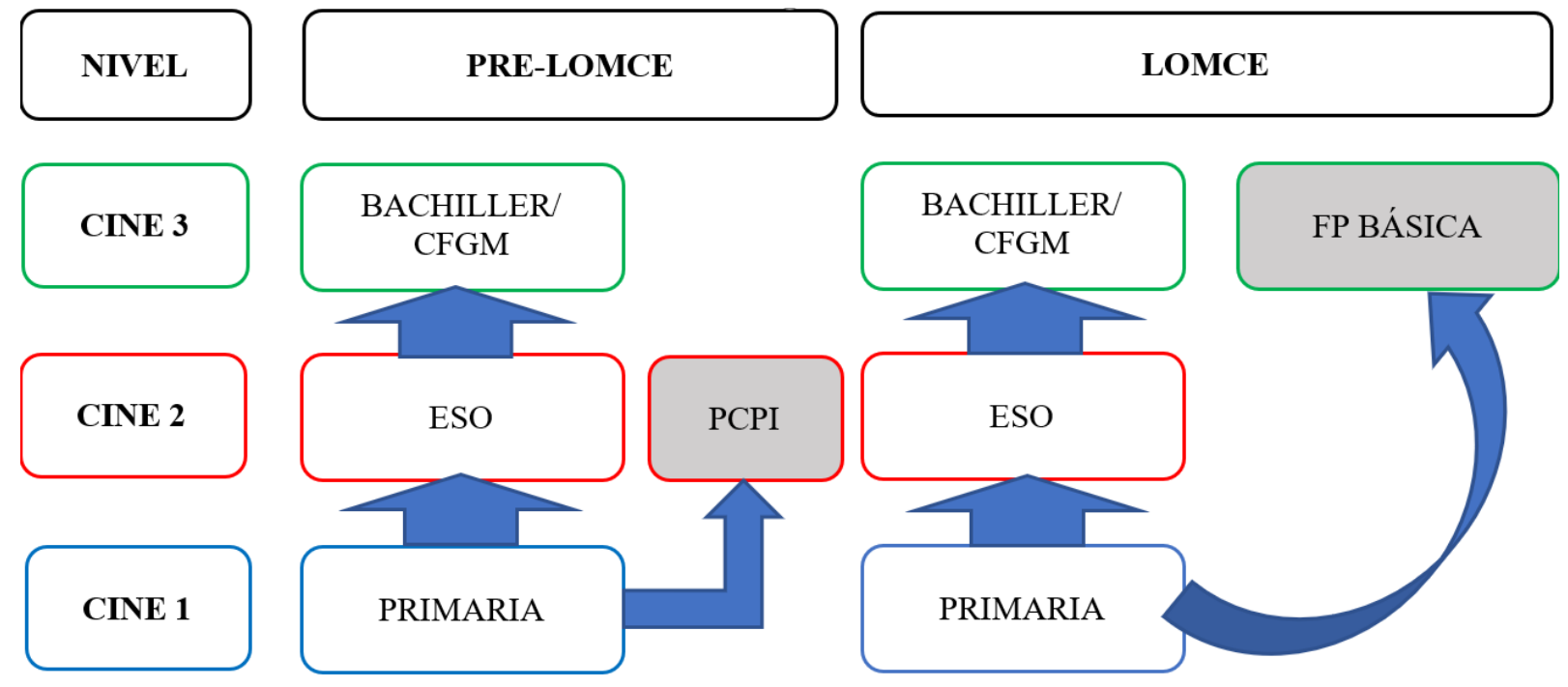

Fuente: Elaboración propia

- Ajuste a los criterios recomendados por la CINE. El diseño está completamente justificado a nivel internacional al cumplir con los criterios establecidos en la clasificación internacional de la UNESCO para ser considerado como nivel CINE 3. Estos criterios son cuatro: edad de inicio (rango de 14 a 16), duración del programa (rango de 2 a 5 años), duración acumulada desde el inicio en el sistema educativo (rango de 11 a 13) y edad final (rango de 17 a 18).

- Edad de inicio: la LOMCE establece el acceso a la FPB a la edad de 15 años (16 en los antiguos PCPI).

- Duración del programa: la FPB se estructura en dos años (un año por curso académico).

- Duración acumulada: en España se comienza a los 6 años, la duración acumulada total al cumplir la edad de 15 (tras terminar $3^{\circ}$ de ESO sin repetir ningún curso), son 9 años. Si sumamos esta duración acumulada a la duración mínima del programa de FPB que se propone en la UNESCO, suma un total de 11 años.

Excepcionalmente se establece la entrada a la FPB tras haber cursado $2^{\circ}$ de ESO (a la edad de 15 años o 14 si cumples 15 ese mismo año de ingreso a la FPB), la duración acumulada entonces del programa formativo FPB sería de 10 años (8 desde primaria más 2 del propio programa), hecho que no cumpliría las recomendaciones de la CINE. Por ello, el acceso desde segundo de ESO solo puede hacerse si has repetido curso.

- Edad final: en principio, entrando con la edad de 15 años y cursando un curso por año, la edad final de 17 o 18 años cumplida. No sucedería lo mismo si, tal y como se establece en la LOMCE (art. 42), se permaneciera 4 años en vez de 2 en el programa, al haber repetido los dos cursos una vez. En este caso, no se cumpliría con las recomendaciones internacionales al finalizar el programa con 19 años. Si 
bien se trataría de una situación excepcional, que no implica a un porcentaje considerable de estudiantes.

\section{Síntesis y punto de partida para la planificación de nuestro estudio}

La valoración de la efectividad de las políticas y medidas implementadas para prevenir el abandono educativo debería conllevar una evaluación en profundidad de su adecuación a los contextos donde se aplican, los procesos de implementación y los resultados obtenidos. Sin embargo, se constata la ausencia de una evaluación sistemática que, con carácter oficial, pueda confirmar el impacto, o no, de las medidas de reducción del abandono. Los resultados que se ofrecen no permiten valorar con precisión el progreso y titulación del alumnado en el sistema educativo postobligatorio. La información disponible está fragmentada en investigaciones académicas que subrayan, principalmente, importantes carencias: los estudiantes de centros de adultos reconocen que si hubieran recibido más orientación profesional no habrían abandonado (Holgueras, 2016), lo que pone de manifiesto la necesidad de reforzar la orientación como vía de prevención; por otra parte, resultados de metaanálisis señalan la necesidad de sistematizar evidencias para justificar el efecto de los programas de orientación y asesoramiento en la reducción del ATEF (Escapa y Julià, 2018).

Conocer cómo promociona el alumnado en las distintas etapas escolares nos permite identificar dónde se produce el desenganche y aproximarnos a una evaluación de resultados de las políticas implementadas, proporcionándonos una línea de partida necesaria para repensar estrategias y medidas de orientación que puedan prevenir y dar respuesta al abandono. Sin embargo, no se ofrece información oficial sobre la evolución de las trayectorias académicas que sigan algún tipo de flexibilización curricular; solo está disponible la progresión del volumen de matrícula y titulados en medidas de iniciación profesional.

Nuestro análisis de la evolución del abandono, a partir de los datos oficiales que se hacen públicos, tiene como objetivo evidenciar las transiciones entre distintas etapas educativas hasta la consecución del nivel CINE 3: ¿cómo se produce la progresión en secundaria obligatoria hacia secundaria postobligatoria? Por otra parte, la nueva conceptualización de la FPB, aun no siendo una propuesta pedagógica radicalmente distinta de las anteriores medidas a las que sustituye, repercute positivamente en el cómputo del ATEF por categorizar este nivel de formación como CINE 3. De forma específica nos interesa conocer el efecto de esta conceptualización de la FPB en el cómputo del abandono: ¿cómo incide la FPB en el cálculo del abandono?, ¿qué implicaciones tiene esto para la orientación educativa?

\section{Método}

Para responder a las preguntas de investigación se han realizado análisis comparativos y longitudinales a partir de la información oficial facilitada por el MEFP. 


\section{Variables e indicadores}

La información analizada recoge las dos variables clave pare el estudio de la promoción de los estudios: matrícula y resultados académicos, obtenidas en las bases de datos que se detallan a continuación:

- Estadísticas de la educación del alumnado matriculado en enseñanzas no universitarias (año 2005 al 2019): http://www.educacionyfp.gob.es/servicios-alciudadano/estadisticas/no-universitaria/alumnado/matriculado.html

- Estadísticas de la educación de los resultados académicos del alumnado en enseñanzas no universitarias (año 2005 a 2017): http://www.educacionyfp.gob.es/servicios-al-ciudadano/estadisticas/nouniversitaria/alumnado/resultados.html

- Estadísticas de la educación del Nivel de Formación, Formación Permanente y Abandono. Transición de la formación al trabajo. Abandono temprano de la educación$\begin{array}{llll}\text { formación (año } & 2010 & \text { a } & \text { 2017): }\end{array}$ http://estadisticas. mecd.gob.es/EducaDynPx/educabase/index.htm?type=pcaxis\&path= /Formacionyml/EPA 2020 05/Aban\&file $=$ pcaxis \&l=s0

Estas bases de datos centralizan la información derivada de las administraciones educativas autonómicas cuyos sistemas informáticos facilitan la gestión de la información escolar. La información sobre matrícula, calificaciones y expedición de títulos queda registrada a nivel autonómico y transferida por completo a las bases de datos nacionales. La información que estas bases de datos aportan no son registros directos de cada uno de los estudiantes, sino el número total de alumnos matriculados o titulados, junto con variables complementarias: sexo, comunidad y provincia, titularidad del centro, y repeticiones de cada alumno. Siendo nuestro objeto de estudio analizar cómo se comporta el ATEF en el cómputo general, nos centraremos expresamente en el volumen de matrícula y resultados conseguidos.

\section{Población}

La información contenida en las bases de datos relativas a matrícula y a resultados académicos recoge los resultados del total de la población escolar en enseñanzas no universitarias de los años 2005 a 2017.

Se han seleccionado los datos correspondientes a las etapas estudiadas: programas de cualificación profesional inicial (por ser el programa al que sustituye la FPB tras la LOMCE), secundaria obligatoria (por certificar CINE 2), bachiller (por certificar CINE 3), formación profesional básica (por certificar CINE 3) y media (por certificar CINE 3), recordando que para no computar como ATEF es necesario obtener el nivel CINE 3. El número total de personas a los que se refieren los datos, al ser el total de personas estudiantes matriculadas y tituladas, asciende a 2.000.000 de estudiantes por cada uno de los años estudiados 


\section{Series temporales}

Los datos públicos disponibles difieren en el año de inicio en función de varios aspectos: los diferentes programas formativos, los propios módulos de estos programas formativos, la referencia a número de matriculados o titulados y, por último, el año de promulgación de la ley educativa que implementa el programa.

En consecuencia, la amplitud de los periodos e intervalos longitudinales estudiados en el apartado resultados difiere en algunos casos al no disponer de una fecha inicial común en todos los análisis. Además, datos como los resultados académicos, no se dispone de ellos a partir de los cursos siguientes al año 2016-2017.

\section{Resultados}

El porcentaje de ATEF viene descendiendo progresivamente en los últimos años, mostrando una reducción mucho mayor en el caso de España en comparación con el conjunto de la Unión Europea.

La reducción del ATEF nos hace pensar que habrá un porcentaje mayor de estudiantes que consiguen titular en niveles postobligatorios, es decir, que consiguen titular de CINE 3 (CFGM y Bachiller en LOE; CFGM, Bachiller y FPB en LOMCE). El análisis de las trayectorias de los estudiantes en el sistema educativo nos pone de evidencia datos de interés para esta valoración, que a continuación pasaremos a explicar, y cuyas conclusiones son claves para contribuir a la mejora de la orientación educativa.

\section{La continuidad hacia el CINE 3: formación profesional media y bachiller}

Se expone a continuación en el gráfico 1 la evolución de los últimos años en el número de egresados en CFGM y Bachillerato.

El número de titulados en FP de Grado Medio registra un incremento notable hasta 2016, aumentando un promedio de 5.000 alumnos por año, aunque el curso 2016-17 registra nuevamente un descenso de titulados. En Bachillerato, se aprecia también una tendencia favorable y sostenida a lo largo de todo el período. 


\section{Gráfico 1}

Número de titulados CFGM y Bachillerato

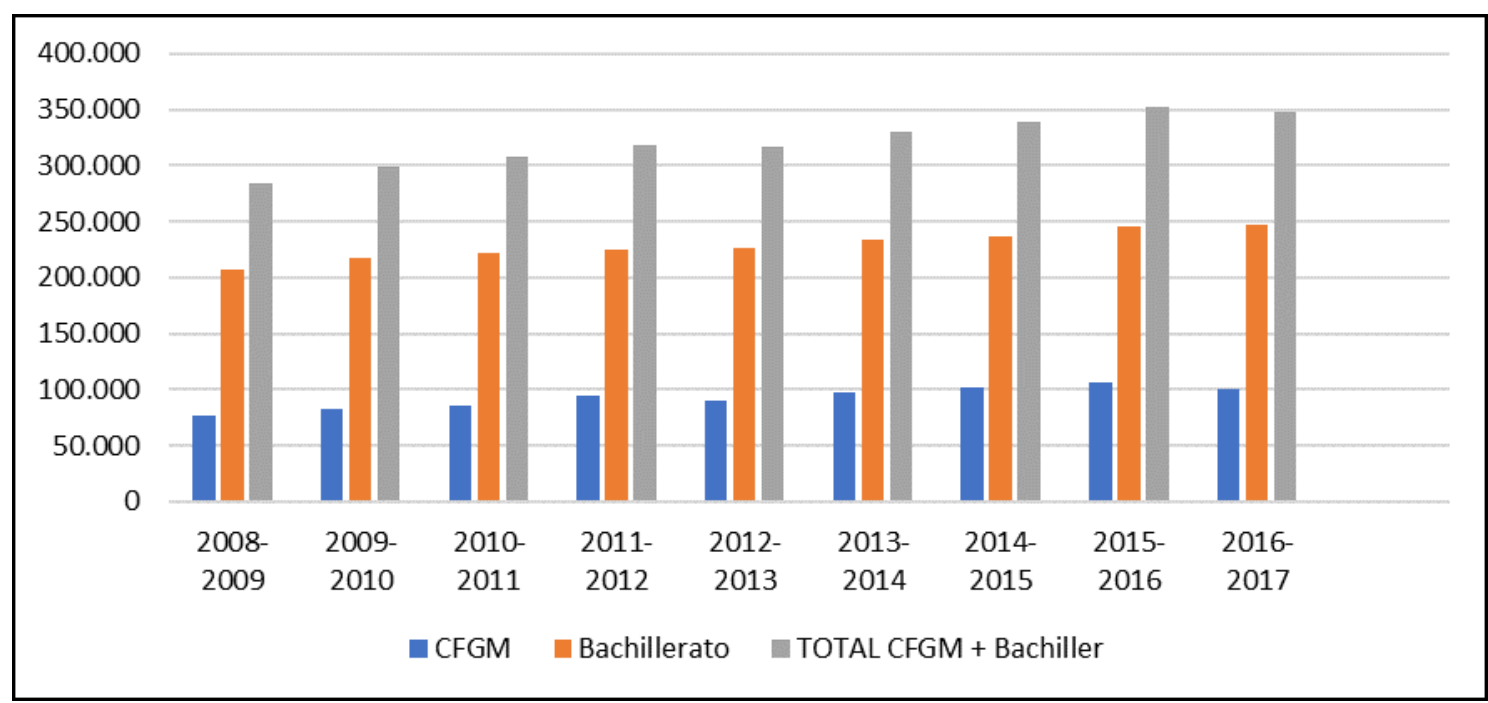

Fuente: Elaboración propia a partir de los datos MEFP

Para valorar la aportación de este dato al análisis del abandono, es necesario relacionarlo con el número de estudiantes que acceden a estos estudios y responder a la pregunta: ¿Hay más estudiantes que consiguen titular en CFGM y Bachiller porque son más los que inician esta etapa educativa? Si se considera conjuntamente a estos titulados y se calcula el porcentaje que representan sobre el total de estudiantes que terminan $4^{\circ}$ de la $\mathrm{ESO}$, se aprecia la siguiente tendencia que se observa en el gráfico 2:

\section{Gráfico 2}

Porcentaje de personas que titulan 4 ESO y terminan CINE 3

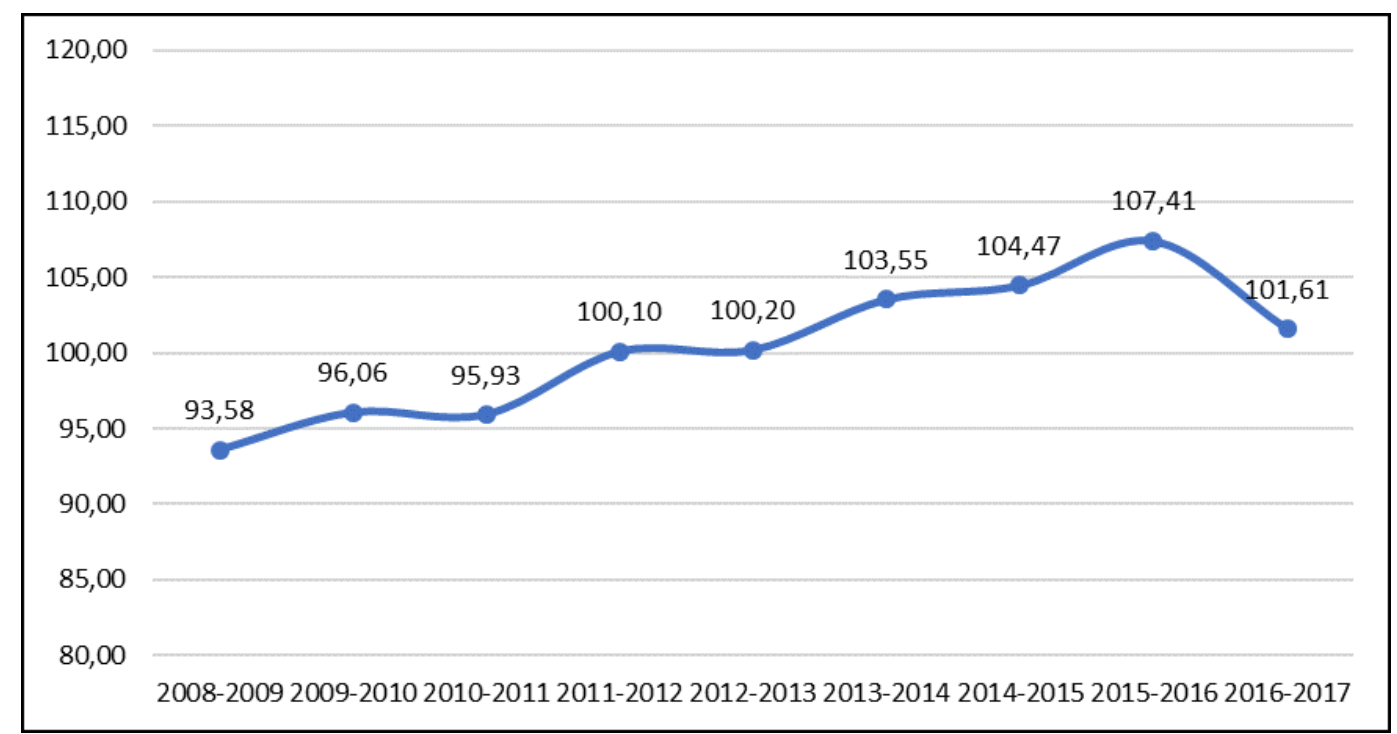

Fuente: Elaboración propia a partir de los datos MEFP 
El período estudiado deja ver un incremento de más de 10 puntos porcentuales, desde 93.58\% en 2008-09 hasta porcentajes superiores al 100\% a partir del año 2011-2012. Este dato, además de indicar que la procedencia a estos estudios no se restringe únicamente a $4^{\circ}$ de ESO, (de mantenerse esta restricción sería imposible justificar porcentajes superiores al 100\%), puede inducir a pensar en una influencia favorable en la reducción del abandono educativo.

No obstante, una correcta interpretación de esta evolución nos exige analizar cuántos iniciaron la secundaria y mostrar cuántos no consiguieron terminar $4^{\circ}$ de ESO.

\section{Gráfico 3}

Abandono de la educación secundaria obligatoria en España

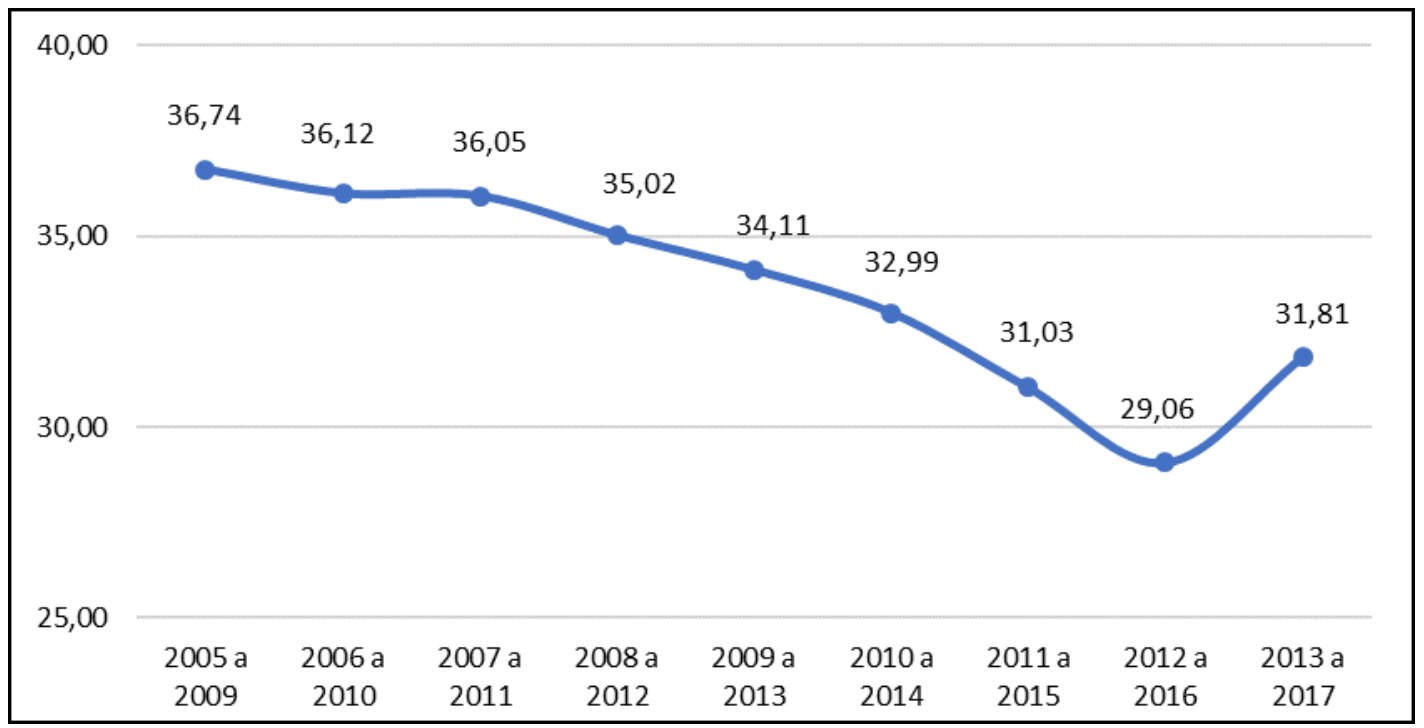

Fuente: Elaboración propia a partir de los datos MEFP

Las cifras muestran que el abandono escolar en la etapa obligatoria disminuye a lo largo del período analizado. Sin embargo, los porcentajes de estudiantes que no obtienen el título de secundaria están cercanos al 30\%. Por tanto, podemos pensar en una justificación de un posible éxito a partir de $4^{\circ}$ de la ESO porque, previamente, ha habido una derivación de estudiantes hacia otros programas en los cuales no se obtiene el grado de secundaria y que quedan fuera de la progresión hacia FP Media o Bachillerato. Estas derivaciones están contempladas en la propia ley educativa que "diversifica" y diferencia a cada estudiante para enviarlo al mejor recurso 0 programa a través de los servicios de orientación.

Para conocer con más detalle la transición en la secundaria obligatoria en los cursos previos mostramos el gráfico 4, donde se indica el número de estudiantes que no llegaron a matricularse en $4^{\circ}$ de ESO en el año teórico en el cual tenían que hacerlo; es decir, si se observa el curso 2010-2011, el número de estudiantes matriculados en 1ํ de ESO 3 años antes (2007-2008) era un $21,56 \%$ más. 


\section{Gráfico 4}

Porcentaje de personas que entran en $1^{\circ}$ ESO y no se matriculan en $4^{\circ}$ ESO

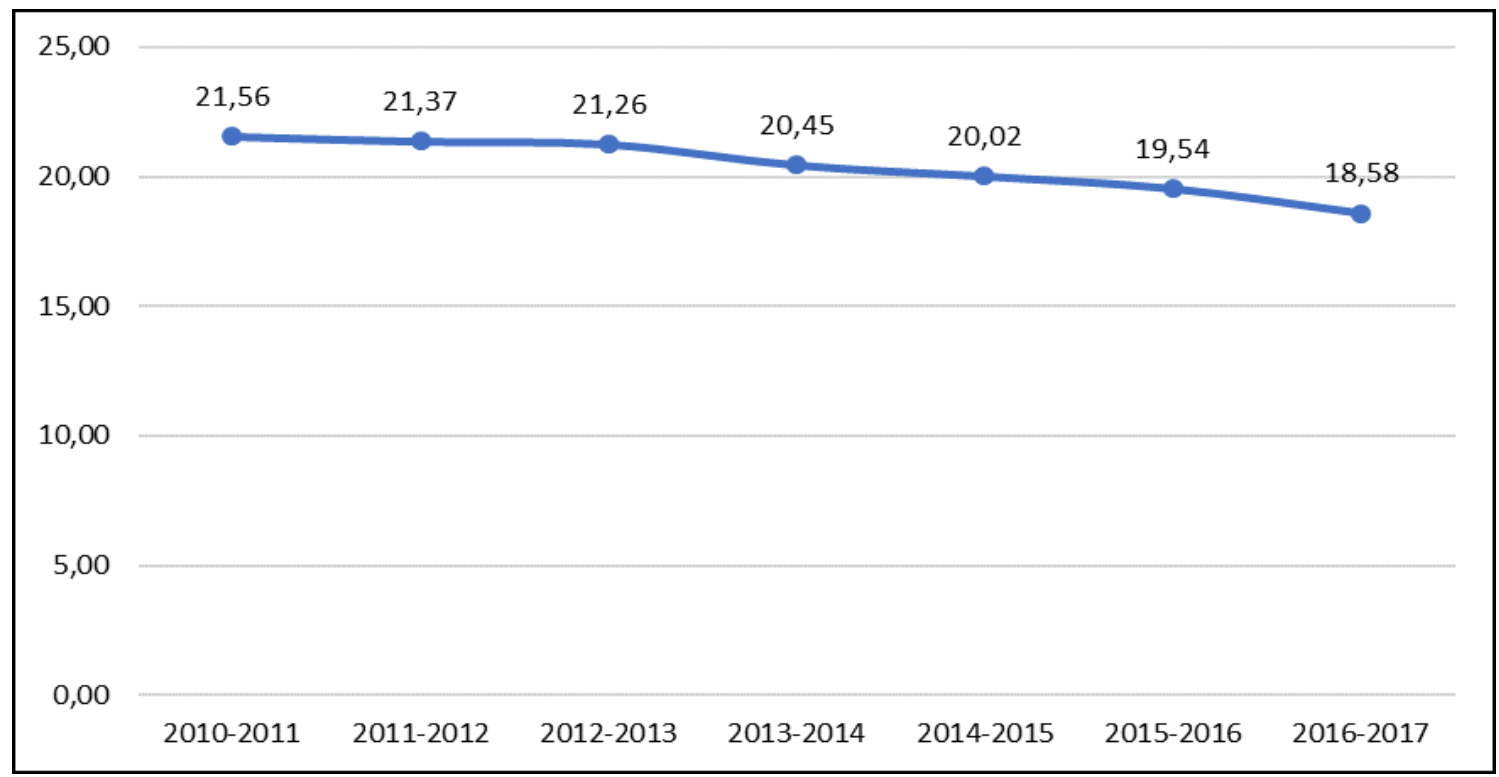

Fuente: Elaboración propia

Se observa que el número de personas que no consiguen llegar a 4ํำ de ESO está en torno al $20 \%$ desde hace varios años.

Desde las estrategias y medidas de orientación educativa se debe poner especial atención a este hecho: la prevalencia de los niveles de desenganche en la educación secundaria obligatoria. Si bien, para completar este análisis hay que contrarrestar el posible efecto de la FPB, cuyo complejo diseño posibilita justificar que los estudiantes que titulan no computen como ATEF. Analizamos a continuación este aspecto.

\section{El efecto de la Formación Profesional Básica}

La incidencia de la FPB en el cómputo del ATEF se comprueba en el gráfico 5.

Se observa que la tendencia que muestran los datos de ATEF sin sumar los titulados en FPB se aproxima al $30 \%$. Mientras que sumando los titulados de FPB la tendencia se reduce a un $26 \%$. Esto quiere decir que, como mínimo, en el momento que las personas que se estén titulando de FPB entren a formar parte y a completar todo el rango de edad de los 18 a los 24 años (hecho que ocurrirá en el año 2023), el ATEF se reducirá aproximadamente en un 3,5\% y, de esta forma, se conseguirá cumplir con el objetivo europeo.

Pero ¿son entonces eficaces las medidas educativas que se están implementando? 


\section{Gráfico 5}

Diferencia en el porcentaje de ATEF contando o no con la FPB

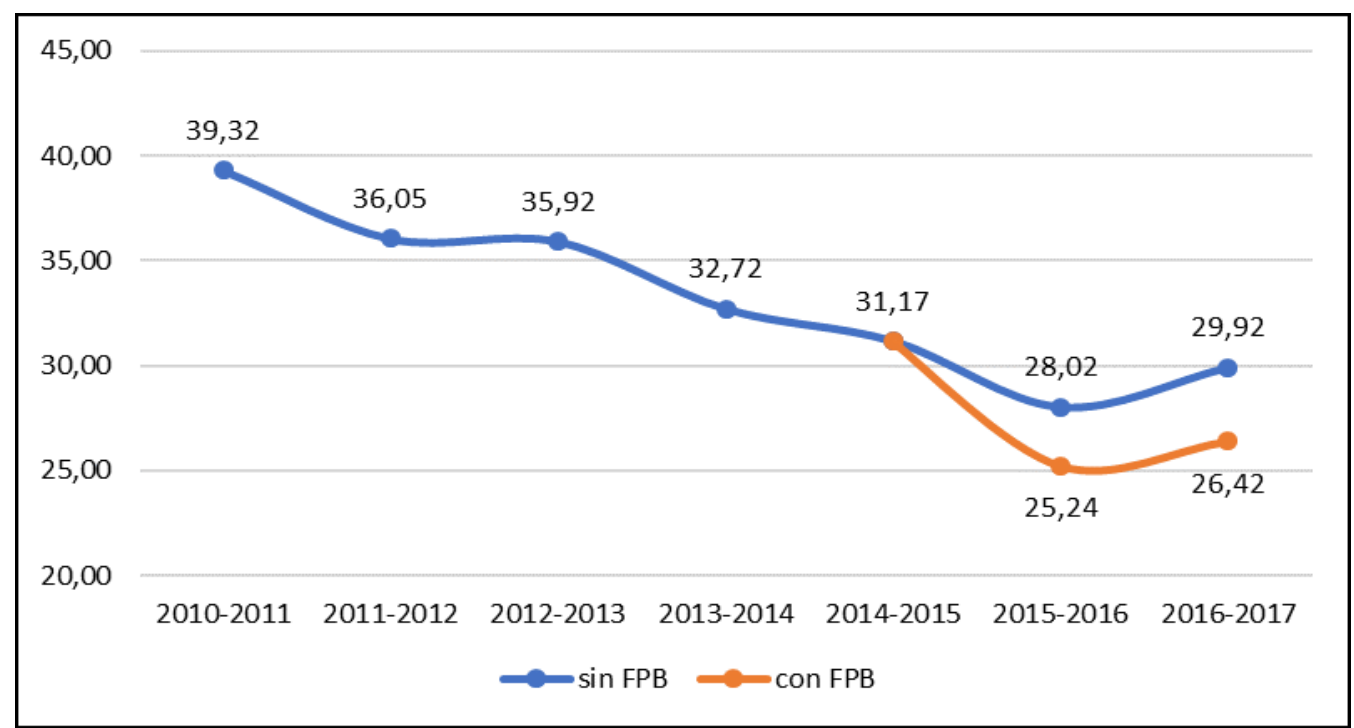

Fuente: Elaboración propia a partir de los datos del MEFP

De la eficacia de la medida de la FPB

Las cifras de éxito en la nueva etapa de FPB no parecen ser muy altas (Gráfico 6). Es cierto que sólo se dispone de los datos de los dos primeros años, pero podemos ir comprobando que del total del número de personas matriculadas solamente unas pocas logran titularse. Aun así, es un número suficiente para reducir el ATEF en casi un $4 \%$.

\section{Gráfico 6}

Porcentaje de éxito y abandono en FPB

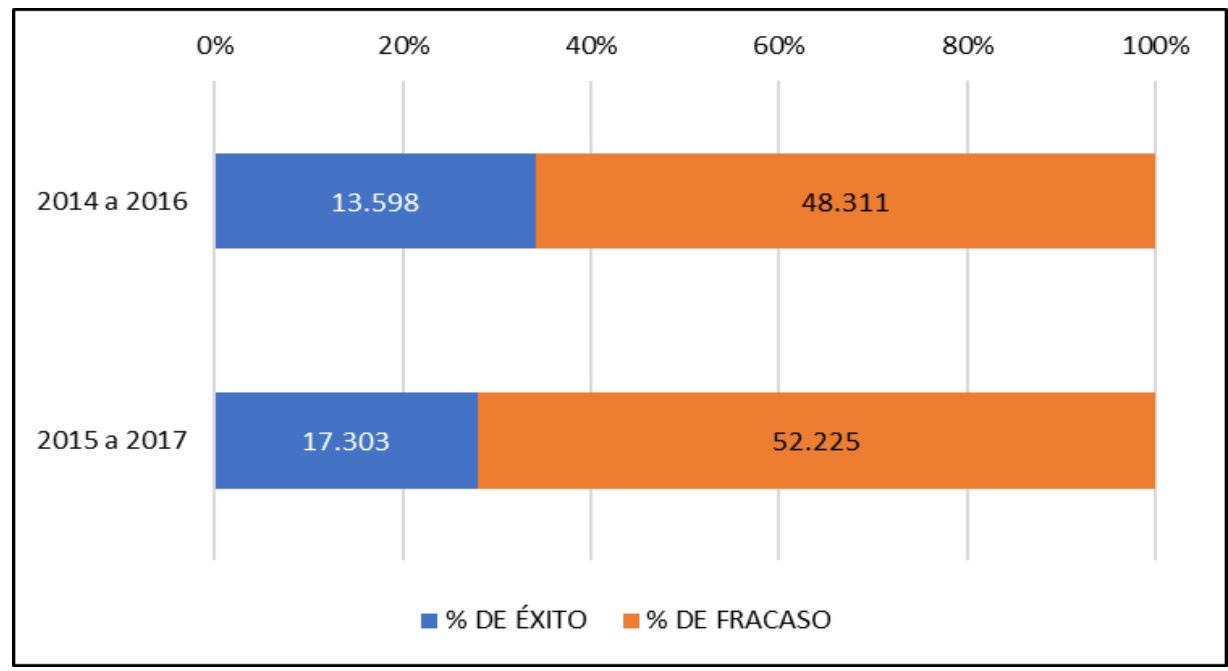

Fuente: Elaboración propia a partir de los datos del MEFP 
Comparando los datos con las personas que se matriculaban en los módulos voluntarios de PCPI para obtener la ESO (gráfico 7), se observa que, aunque el número de personas que titula es similar, el porcentaje de éxito y la eficacia de estos programas eran muy diferentes. De las aproximadamente 65.000 personas por curso académico que se han matriculado de la FPB durante estos años, únicamente consiguieron titular 15.000. Sin embargo, de las 20.000 personas matriculadas en los módulos de la ESO en el PCPI por año académico, conseguían titular cerca de 14.000 .

\section{Gráfico 7}

Porcentaje de éxito y abandono en PCPI

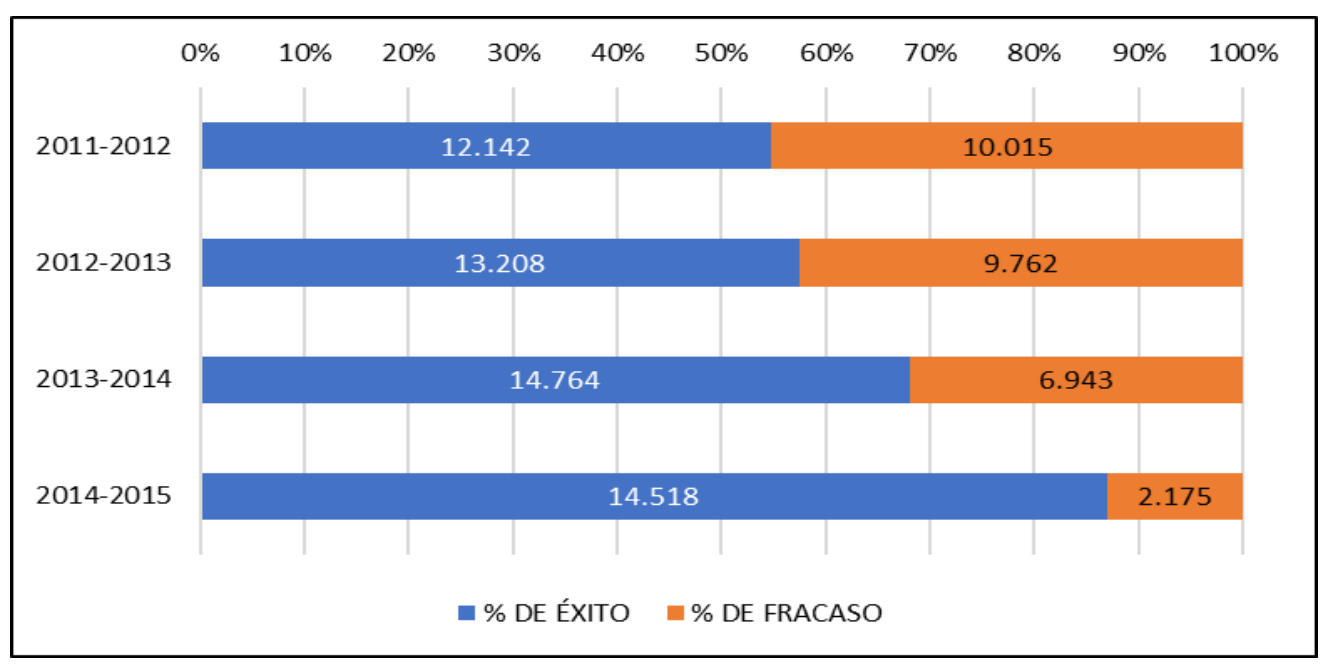

Fuente: Elaboración propia a partir de los datos del MEFP

En el gráfico 8 podemos ver esta comparación entre los dos programas formativos, mostrando que las personas que actualmente titulan de CINE 3, son las que anteriormente titulaban de CINE 2:

\section{Gráfico 8}

Número de personas matriculadas y tituladas en el módulo de PCPI de ESO y FPB

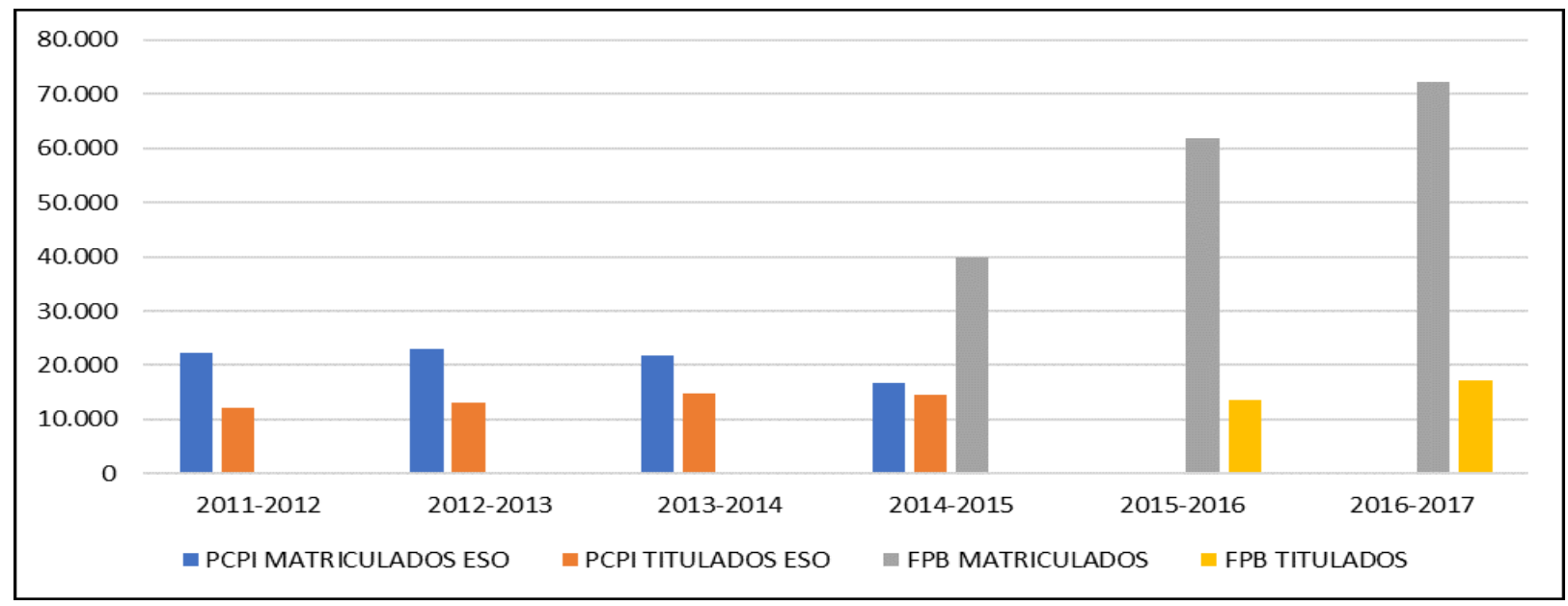

Fuente: Elaboración propia a partir de los datos del MEFP 


\section{Conclusiones y Discusión}

La preocupación por el ATEF es una constante en las políticas educativas y orientadoras tanto a nivel europeo como nacional. Preocupación que se traduce en porcentajes como hitos a alcanzar en las tasas de reducción del abandono. El interés por la cifra se antepone a la revisión de las prácticas. Nos encontramos así en un panorama complejo: las medidas impulsadas por la LOE y LOMCE para prevenir y dar respuesta al ATEF no son objeto de evaluación por parte de las administraciones públicas; se focaliza la atención en el resultado más que en los procesos educativos y de orientación. La cuantificación del abandono educativo no permite comprender con detalle qué está ocurriendo en la promoción de los estudiantes desde secundaria hasta niveles postobligatorios.

Si atendemos a los resultados que se derivan de esta cuantificación, podríamos pensar que son positivos, pues el porcentaje de ATEF viene disminuyendo desde 2009. Pero se necesita una panorámica más compleja para comprender esta evolución.

EI ATEF se reduce debido al volumen creciente de titulados CINE 3 (Gráfico1), pues la mayoría de las personas que han titulado en secundaria obligatoria continúan estudiando con éxito (Gráfico 2). Sin embargo, se comprueba que un $30 \%$ del alumnado que comienza sus estudios en ESO, no llegan a terminarlos (Gráfico 3). Esta cifra se relaciona parcialmente con el alto volumen de repetidores. Pero la repetición no se ha mostrado como un mecanismo eficaz de compensación educativa; de hecho, repetir es uno de los factores que se asocian notablemente con la decisión posterior de abandonar el sistema escolar (Tarabini et al., 2016), aspecto que debe tenerse en cuenta desde la orientación educativa. El análisis del momento en que se produce el desenganche en la secundaria obligatoria revela que aproximadamente dos terceras partes lo hacen antes de llegar a $4^{\circ}$ y el otro tercio ya en $4^{\circ}$ (gráficos 3, y 4$)$. Desde el punto de vista de la orientación este dato plantea la necesidad de una evaluación de la adecuación y eficacia de las medidas de flexibilización curricular. Este hecho viene manteniéndose en los últimos años, sea en el sistema educativo regulado por la LOE o el regulado por la LOMCE. En el momento actual, la reducción del cómputo del ATEF está relacionada con la distinta consideración de la FPB y los PCPI's a los que sustituye. La mayoría de las personas que no conseguían concluir la ESO durante la LOE, eran orientadas hacia los PCPI's, programas en los cuales no se certificaba un CINE 3. Con la LOMCE, se sustituyeron estos programas por la FPB, permitiendo la obtención del nivel CINE 3 (gráfico 8). Sin embargo, como se observa en los gráficos 6 y 7, los antiguos PCPI's presentaban mayores tasas de éxito en la obtención del graduado en ESO. Como señalan Sarcedo-Gorgoso et al. (2017), la gravedad de la situación de los PCPI's se agrava aún más con la FPB, puesto que los estudiantes que abandonan lo hacen sin ningún tipo de cualificación profesional ni certificación académica, dejándoles en una situación de mayor vulnerabilidad.

Las implicaciones que este análisis tiene para la orientación educativa son varias. En primer lugar, se reconocen los logros en la orientación ofrecida al término de la secundaria, facilitando que los estudiantes prosigan su trayectoria con éxito. Sin embargo, al imponerse desde Europa en el discurso educativo el indicador de abandono como personas que no consiguen titular en la secundaria postobligatoria, hemos invisibilizado otras formas de desenganche educativo en la etapa obligatoria previa. Por tanto, una segunda implicación para la orientación plantea la necesidad de valorar el funcionamiento y resultados de las medidas de flexibilización que desde los centros educativos se realizan para cierto tipo de alumnado. Se necesita un seguimiento y 
evaluación que nos permita conocer las trayectorias de estos estudiantes. Conocer dónde y cómo termina nuestro alumnado su trayectoria académica es fundamental a la hora de establecer medidas concretas para cada una de estas personas desde la etapa secundaria. Conocer qué ocurre con, prácticamente, el $70 \%$ del alumnado que no termina FPB, o el $30 \%$ que no termina la ESO, debería ser una de las principales prioridades de la investigación en orientación educativa. Que el abandono disminuya, no implica, como mostramos en los resultados, que el sistema educativo mejore. Siguiendo la tendencia actual alcanzaremos en 2023 el logro del objetivo europeo sin que nada haya mejorado sustancialmente. Esto puede resultar perverso y, peor aún, puede llevarnos a devaluar el sistema formativo de Formación Profesional como opción flexible y de calidad. Si se contempla la formación profesional como una vía para reducir el abandono, deben repensarse problemas relevantes que limitan un seguimiento de estos estudios adecuado a los intereses del estudiantado, como son la sobredemanda, la escasa variedad de la oferta y el carácter repetitivo, así como su falta de atractivo (Abiétar-López et al., 2017; Feria-Viceo, 2017; Sarcedo-Gorogoso et al., 2017). Desde la acción orientadora es algo que debemos considerar para seguir construyendo proyectos profesionales y vitales de calidad, situando a las personas en el centro de sus correspondientes trayectorias vitales (Romero Rodríguez, 2004).

El esfuerzo por ajustar el indicador de ATEF al nivel establecido por Europa exige atender no solo al resultado sino, principalmente, al proceso educativo. Si se focaliza únicamente en el resultado, diferentes factores macroestructurales como la facilidad con la que el mercado de trabajo acoge a los jóvenes con bajo nivel de estudios, sobre todo en las economías turísticas y en el sector de la construcción, podrían ser responsables de la mejora de las cifras. Desde el inicio de la crisis económica se ha producido un descenso en las ofertas de trabajo y un aumento de la precariedad, hechos que influyen en la reducción del abandono de la educación más allá de las políticas educativas desarrolladas en nuestro país. Por ello, la preocupación por el abandono no puede invertir el centro de interés del sistema educativo: el/la estudiante.

En este sentido, la orientación debe situar a la persona como centro de atención y valorar cómo se van perfilando las trayectorias escolares de estudiantes de secundaria hasta elegir la FPB, cuidando toda la etapa secundaria y, especialmente, prestando atención en los momentos donde empieza a producirse el desenganche. La tendencia de las reformas de los últimos años en gran parte de los países europeos es la introducción de la orientación no solo como un servicio de apoyo a la escuela sino como parte del currículum y dirigida a todos los y las estudiantes en la educación secundaria (Comisión Europea, 2019a).

A partir de este estudio cabría señalar otras propuestas de acción que consideramos clave en la prevención del abandono. A nivel de administraciones educativas se debería exigir una medida final del ATEF, basada en la progresión del estudiante a lo largo de su escolaridad. El reciente informe europeo sobre indicadores estructurales de los sistemas educativos de los estados miembros destaca la necesidad de apoyarse en datos. En el análisis y evaluación del ATEF estos datos deben proceder del registro de estudiantes. Los distintos países de la UE están introduciendo medidas que modifican y amplían la información recogida en las encuestas de población activa (Comisión Europea, 2019b). En el caso de España, se subraya la carencia de registros basados en resultados de estudiantes como forma de cálculo del abandono. Resulta insuficiente la información disponible para comprender qué está ocurriendo y ofrecer la atención necesaria desde la orientación y acción tutorial (Morentin-Encina y Ballesteros, 2020). Las conclusiones del estudio realizado por el Centro Europeo para el Desarrollo de la Formación Profesional (Cedefop, 2016) sobre el ATEF, ponen de manifiesto recomendaciones clave para la redefinición del indicador y el desarrollo de sistemas de medida que permitan monitorizar el ATEF desde un enfoque comprensivo, incluyendo la recogida y análisis de información cualitativa.

Por otra parte, estas mismas administraciones educativas deberían facilitar la flexibilidad y permeabilidad de los itinerarios, ofreciendo la orientación necesaria que permita valorarlos como vías de aprendizaje a lo largo de la vida. 
La preocupación por el ATEF está presente en el desarrollo cotidiano de la tutoría y orientación. Por ello, a nivel de práctica orientadora se necesita potenciar estrategias que motiven el compromiso del estudiante con la educación escolar (Montero y González, 2002; Miñaca y Hervás, 2013). En este sentido, la investigación en orientación nos permite transferir aprendizajes relevantes que favorecen el sentimiento de pertenencia a la comunidad escolar. El abandono escolar no es un problema de los estudiantes, es un problema de la comunidad educativa. Por ello, se requiere una cohesión de todos los agentes para prevenirlo y dar respuestas adecuadas. Las aportaciones de la orientación comunitaria (Martín Algarra, 2015; Morales, 2020) son especialmente interesantes en este sentido: hacer partícipe al profesorado en el plan de orientación académica y profesional, fortalecer la vinculación de las familias con el centro y dotar a los estudiantes de vías de participación en aspectos curriculares y en la dinámica escolar.

Algunas limitaciones de esta investigación están relacionadas con los propios datos que se ofrecen desde el MEFP. Estas bases de datos no permiten trabajar con puntuaciones directas derivadas de los registros escolares; la información disponible posibilita únicamente el cómputo general de estudiantes en cada curso académico y etapa educativa, permitiendo segmentar por sexo, comunidad autónoma/provincia, tipo de promoción (con/sin materias pendientes), y titularidad del centro. Dichas variables no facilitan el estudio de las causas del abandono desde una perspectiva pedagógica interesada en evaluar el efecto de las prácticas y acciones educativas que tienen lugar en los centros. No constan tampoco datos de medidas de diversificación y refuerzo, imposibilitando valorar su impacto en los resultados escolares y en la prevención del ATEF. Asimismo, análisis longitudinales de las trayectorias individuales, que pusieran de manifiesto dónde se producen los desenganches y discontinuidades, no pueden ser realizados a partir de la información ofrecida. Además, los últimos datos publicados remiten al curso 18-19, limitando la actualidad de la información.

Los resultados derivados de nuestra investigación subrayan el interés del seguimiento y evaluación de las actuales medidas de prevención del ATEF, con especial atención a la FPB, considerando que el análisis de sus resultados y la continuidad de las trayectorias, educativas o laborales, son aspectos clave para la orientación. Numerosos estudios (Cedefop, 2016; CerdàNavarro et al., 2019) señalan que la orientación académica recibida y la oferta formativa existente tienen una gran influencia en el proceso de elección de los estudios de formación profesional. De hecho, la insatisfacción con la formación elegida (bien por no ser la primera opción elegida bien por no adaptarse a las expectativas del alumnado) es una de las principales causas de abandono en la formación profesional (tanto en el CFGM como en la FPB). Por tanto, el desarrollo de una orientación académica es fundamental en la prevención del abandono.

\section{Referencias bibliográficas}

Abiétar-López, M., Navas-Saurin, A.A., Marhuenda-Fluixá, F. y Salvà-Mut, F. (2017). La construcción de subjetividades en itinerarios de fracaso escolar. Itinerarios de inserción sociolaboral para adolescentes en riesgo. Psychosocial Intervention, 26(1), 39-45. https//doi.org/10.1016/..psi.2016.07.002

Alegre, M. Á. (2010). Casi-mercados, segregación escolar y desigualdad educativa: una trilogía con final abierto. Educação y Sociedade, 31(113), $1157-1178$. https://doi.org/10.1590/S0101-73302010000400006 
Amer Fernández, J. y Mir Gual, A. (2017). Los procesos de implementación de los programas de mejora del rendimiento (PMAR). Perspectivas del profesorado, el alumnado y las familias. Revista Española de Orientación y Psicopedagogía, 28(3), 133-150. https://doi.org/10.5944/reop.vol.28.num.3.2017.21623

Aramendi Jáuregui, P. y Vega Fuente, A. (2013). Los Programas de Cualificación Profesional Inicial. La perspectiva del alumnado del País Vasco. Revista de Educación, 360, 436-460. https://doi.org/10.4438/1988-592X-RE-2011-360-122

Blasco, J. y Casado, D. (coord.) (2013). Evaluación de los programas de cualificación profesional inicial (PCPI). Ivàlua. Institut Català d'Avaluació de Polítiques Públiques. https://www.educacionyfp.gob.es/

Bolívar, A. (2013). La nueva FP Básica: ¿"trucos estadísticos" para rebajar el abandono, vía de salida o verdadera cualificación profesional? Ideal en clase, 30 de noviembre.

Bonal, X. (2018). UNESCO. La política educativa ante el reto de la segregación escolar en Cataluña. Instituto Internacional de Planeamiento de la Educación-UNESCO. https://repositorio.minedu.gob.pe/

Cedefop (2016). Leaving education early: putting vocational education and training centre stage. Volume I: investigating causes and extent. Publications Office. https://dx.doi.org/10.2801/893397

Cerdà-Navarro, A., Salva-Mut, F., y Comas-Forgas, R. (2019). A Typology of Students in Intermediate Vocational Education and Training Programs based on Student Engagement Factors, Sociodemographic Characteristics and Intentions of Dropping out. European Journal of Education, 54(4), 635-650. https://doi.org/10.1111/ejed.12361

Clasificación Nacional de Educación (2016). Introducción y aspectos generales. Instituto Nacional de Estadística. https://www.ine.es/, https://www.educacionyfp.gob.es/

Comisión Europea (2010). Europa 2020: la estrategia de la Unión Europea para el crecimiento y la ocupación. Publications Office of the European Union. https://eur-lex.europa.eu/

Comisión Europea (2019a). Structural Indicators for Monitoring Education and Training Systems in Europe - 2019: Overview of major reforms since 2015. Eurydice Report. Publications Office of the European Union. https://eur-lex.europa.eu/

Comisión Europea (2019b). Education and Training. Monitor 2019. Publications Office of the European Union. https://eur-lex.europa.eu/

Consejo de la Unión Europea (2003). Council conclusions of 5/6 May 2003 on reference levels of european average performance in education and training (Benchmarks). Oficina de Publicaciones de la Unión Europea.

Corujo Vélez, Ma․ C., Méndez García, S. y Rodríguez Carmona, A. M.a․ (2018). Valoración de los Programas de Mejora del Aprendizaje y del Rendimiento desde la visión de sus protagonistas en cuatro poblaciones de la provincia de Sevilla. Tendencias pedagógicas, 32, 31-48. http://dx.doi.org/10.15366/tp2018.32.003

Escapa, S. y Julià, A. (2018). ¿Qué impacto tienen en los alumnos los programas de orientación y asesoramiento? Fundació Jaume Bofill e Instituto Català d'Avaluació de Polítiques Públiques. 
Feria-Viceo, A. (2017). Una revisión de las políticas educativas contra el abandono escolar prematuro: el papel de la formación profesional. Temas de Educación, 23(2), 252-265. https://revistaschilenas.uchile.cl/handle/2250/34232

Holgueras González, A. I. (2016). Análisis de la influencia de la orientación profesional en los jóvenes en situación de abandono escolar. Educatio Siglo XXI, 34(1), 137-156. https://doi.org/10.6018/j/253251

Icart Trefí, M. y Vilà Suñé, M. (2019). Buenas prácticas de los programas de diversificación curricular desde la perspectiva de los profesionales. Revista de Educación Inclusiva, 12(2), 8-24. https://revistaeducacioninclusiva.es/index.php/REl/article/view/487/482

LOE (2006). Ley Orgánica 2/2006, de 3 de mayo, de Educación. https://www.boe.es/buscar/pdf/2006/BOE-A-2006-7899-consolidado.pdf

LOMCE (2013). Ley Orgánica 8/2013, de 9 de diciembre, para la mejora de la calidad educativa. https://www.boe.es/buscar/pdf/2013/BOE-A-2013-12886-consolidado.pdf

Marín Marín, J.A., García Carmona, M. y Sola Reche, J.M. (2014). Reflexión y análisis sobre los Programas de Cualificación Profesional Inicial como medida de inclusión social y educativa en Andalucía (España). REICE. Revista Iberoamericana sobre Calidad, Eficacia y Cambio en Educación, 12(1), 83-102. https://www.redalyc.org/pdf/551/55129541006.pdf

Martín Algarra, A. M. a y claustro de profesores (2015). Intervención psicoeducativa con alumnos en riesgo de abandono escolar y con sus familias. Revista del Consejo Escolar del Estado $4(7), 124-132$.

Martín Ortega, E. (2000). Programas de diversificación curricular: uso, pero no abuso. Cuadernos de Pedagogía, 293, 18-22. http://hdl.handle.net/11162/38097

Martínez García, J. S. (2012). Fracaso escolar y comunidades autónomas. En M. Puelles (ed.) El fracaso escolar en el Estado de las autonomías. Wolters Kluwer.

Miñaca, I. y Hervás, M. (2013). Intervenciones dirigidas a la prevención del fracaso y abandono escolar: Un estudio de revisión. Revista Española de Educación Comparada, 21, 203-220. https://doi.org/10.5944/reec.21.2013.7620

Montero Fernández, M. y González Ponte, L. (2002). Cómo mejorar la autorregulación del estudio en educación secundaria. Valoración de un programa de acción tutorial. Contextos Educativos, 5, 215-226. http://hdl.handle.net/11162/47571

Morales, J. (2020). El rol orientador del docente en el contexto comunitario. Revista Española de $\begin{array}{llll}\text { Orientación } & y & \text { Psicopedagogía, } & 31(2),\end{array}$ https://doi.org/10.5944/reop.vol.31.num.2.2020.27984

Morentin-Encina, J. y Ballesteros Velázquez, B. (2020). Tanto por cierto: Análisis de la medida del Abandono Temprano de la Educación y Formación. Revista de Educación, 389, 143-176. https://doi.org/10.4438/1988-592X-RE-2020-389-458

Navarro Hinojosa, R. (2006). Los Programas de Diversificación Curricular: ¿qué opinan los alumnos que los han cursado? Revista Española de Pedagogía, 233(1), 123-142. https://revistadepedagogia.org/

Romero Rodríguez, S. (2004). Aprender a construir proyectos profesionales y vitales. Revista Española de Orientación y Psicopedagogía, 15(2), 337-354. https://doi.org/10.5944/reop.vol.15.num.2.2004.11637 
Romero Rodríguez, S., Álvarez Rojo, V., García Gómez, S., Gil Flores, J., Gutiérrez Rodríguez, A., Seco Fernández, M., Jaén Martínez, A., Martín Padilla, A., Martínez del Río, C., Molina García, L. y Santos López, C. (2012). El alumnado de formación profesional inicial en Andalucía y sus necesidades de orientación: algunas aportaciones. Revista Española de Orientación y Psicopedagogía, 23(2), 4 -21.

https://doi.org/10.5944/reop.vol.23.num.2.2012.11404

Romero-Rodríguez, S., Seco-Fernández, M. y Lugo-Muñoz, M. (2015). Orientar desde el Ser: algunas aportaciones del programa Orient@cual para la elaboración del proyecto profesional y vital de alumnado de PCPI y CFGM. Revista Electrónica Interuniversitaria de Formación del Profesorado, 18(2), 75-89. http://dx.doi.org/10.6018/reifop.18.2.219121

Salvá-Mut, F., Quintana-Murci, E. y Desmarais, D. (2014). Inclusion and exclusion factors in adult education of youth with a low educational level in Spain. European Journal for Research on the Education and Learning of Adults, 1-15. http://dx.doi.org/10.3384/rela.20007426.rela0121

Sarcedo Gorgoso, Ma C., Santos, Maㅡ C. y Sanjuán Roca, Ma del Mar (2017). La formación profesional básica, ¿alternativa al fracaso escolar? Revista de Educación, 378, 78-112. https://doi.org/10.4438/1988-592X-RE-2017-378-362

Tarabini, A. y Montes, A. (2015). La agenda política contra el abandono escolar prematuro en España: la LOMCE contra las evidencias internacionales. Avances de supervisión educativa, 23, 1-20. https://doi.org/10.23824/ase.v0i23.20

Tarabini, A., Bonal, X., Castejón, A., Curran, M. y Montes, A. (2016). Los principios de un sistema educativo que no deje nadie atrás. Save the children.

Torres Santomé, J. (2008). Diversidad cultural y contenidos escolares. Revista de Educación, 345, 83-110. https://www.educacionyfp.gob.es/revista-de-educacion/

Torres Santomé, J. (2017). Políticas educativas y construcción de personalidades neoliberales y neocolonialistas. Morata.

Fecha de entrada: 28 septiembre 2020

Fecha de revisión: 6 noviembre 2020

Fecha de aceptación: 13 noviembre 2020 